\title{
Subprodutos utilizados na alimentação de frangos de corte
}

\section{Aline Ferreira Amorim*, Gerson Fausto da Silva², Kênia Ferreira Rodrigues², Joana Patrícia Lira de Sousa ${ }^{3}$, José Ailton Rodrigues Soares ${ }^{4}$}

${ }^{I}$ Professora Mestre do Instituto Federal de Educação, Ciência e Tecnologia do Estado do Tocantins - IFTO Campus Dianópolis

${ }^{2}$ Professores Doutores da Universidade Federal do Tocantins - UFT - Campus Araguaína

${ }^{3}$ Professora Doutora do Instituto Federal de Educação, Ciência e Tecnologia do Estado do Tocantins - IFTO Campus Dianópolis

${ }^{4}$ Professor Especialista do Instituto Federal de Educação, Ciência e Tecnologia do Estado do Tocantins - IFTO

- Campus Palmas

*Autor para correspondência, E-mail: alineamorim19@hotmail.com

RESUMO. Atualmente as pesquisas em nutrição de aves estão voltadas à utilização de subprodutos com o intuito de minimizar o seu descarte no meio ambiente e diminuição dos custos na fabricação de rações. Inúmeros são os subprodutos produzidos pelo Brasil e os estudos nessa área são de grande importância. Para a utilização desses subprodutos na alimentação animal é necessário conhecimento de sua composição bromatológica e os melhores níveis de utilização que devem atender as exigências em cada fase de produção. Objetivou-se com esta revisão abordar trabalhos científicos que apontem a utilização de subprodutos de origem vegetal e animal na alimentação de frangos de corte.

Palavras chaves: produção animal, avicultura, resíduos agroindustriais

\section{By-products used to feed broiler}

ABSTRACT. Currently research in poultry nutrition is directed to the use of by-products in order to minimize their discharge to the environment and lower costs in the manufacture of animal feed. Countless are the byproducts produced by Brazil and studies in this area are of great importance. For the use of these by-products in animal feed is necessary knowledge of their chemical composition and the highest levels of use that must meet the requirements at each stage of production. The objective of this review to address scientific papers that show the use of by-products of vegetable and animal origin in feed for broilers.

Key words: animal husbandry, poultry farming, agro-industrial residues

\section{Introdução}

A avicultura é uma atividade que tem se expandido cada vez mais nos diversos países, segundo dados da (FAPRI, 2015) a produção de carne de frango no Brasil chegou a 12,230 milhões de toneladas em 2010, com um crescimento de $11,4 \%$ em relação a 2009 , se aproximando da China, que hoje é o segundo maior produtor mundial com 12,550 milhões de toneladas de carne de frango produzidas em 2010, ficando esta abaixo apenas dos Estados Unidos, com produção de 16,648 milhões de toneladas de carne de frango. Do volume total de carne de frango produzido no Brasil $69 \%$ foi destinado ao consumo interno, e $31 \%$ para as exportações. Tal crescimento se deve, entre outros fatores, a implementação de novas tecnologias aliados a capacitação de técnicos favorecendo o desenvolvimento correto dos manejos no ciclo de produção.

Por outro lado, de acordo com Andriguetto et al. (2002), a alimentação entra com aproximadamente $75 \%$ dos custos de produção na avicultura comercial e a matéria prima comumente utilizada, milho e o farelo de soja, representam a maior parcela da ração; tornando-a mais onerosa.

Nesse sentido, o estudo das fontes alternativas de alimentos a esses ingredientes possui a finalidade de, além de determinar o nível de inclusão, baratear o custo da ração sem deixar de fornecer os nutrientes essenciais para o bom desempenho das aves. Para atender a esse objetivo, a indústria alimentícia gera enormes 
quantidades de resíduos passíveis de serem utilizados na alimentação animal, além de serem empregados na adubação orgânica e geração de energia, portanto, reduzindo a poluição ambiental.

Objetivou-se com esta revisão abordar trabalhos científicos que apontem a utilização de resíduos agroindustriais de origem animal e vegetal com potencial para a alimentação de frangos de corte.

\section{Revisão}

Apesar da diversidade de subprodutos de origem animal e vegetal e do seu potencial para a alimentação animal, existem alguns fatores anti nutricionais presentes nesses subprodutos que podem diminuir a digestibilidade dos nutrientes, afetando o desempenho animal. E mesmo existindo procedimentos para inativar essas substâncias, nem sempre o resultado é satisfatório (Fialho \& Barbosa, 2008).

Segundo Andriguetto et al. (2002), os fatores anti nutricionais são substâncias presentes nos alimentos que se complexam ou interagem com outras substâncias necessárias ao organismo prejudicando a biodisponibilidade de alguns nutrientes e, portanto, de acordo com Fialho \& Barbosa (2008), acarretando mudanças no perfil das exigências nutricionais, nas diferentes fases do ciclo produtivo, afetando diretamente o desempenho dos animais.

O método de processamento dos resíduos é outro fator que deve ser levado em consideração no balanceamento das rações. Tem sido constatadas alterações em sua composição, de acordo com a metodologia empregada, prejudicando o ideal atendimento as exigências nutricionais das aves (Fialho \& Barbosa, 2008).

\section{Alimentos de origem vegetal}

\section{Babaçu}

O babaçu (Orbignya martiana), também conhecido como bauaçu, baguaçu, coco-demacaco, coco-de-palmeira, coco-naiá, cocopindoba, palha-branca; no espanhol como babasú, shapaja, cusi, catirina e no inglês babasu palm, é uma planta comum aos estados do Maranhão, Piauí, Pará, Mato Grosso e Tocantins, sendo considerada uma planta nativa do Maranhão. Pertence a família das palmáceas Arecaceae, dotada de frutos com sementes oleaginosas e comestíveis, das quais se extrai um óleo empregado, sobretudo, na alimentação humana e remédios, além de ser alvo de pesquisas avançadas para a fabricação de biocombustíveis (Machado et al., 2006).

Dos subprodutos do babaçu destaca o farelo de babaçu, torta de babaçu e farinha amilácea fina do babaçu.

\section{Farelo de babaçu}

O farelo de babaçu é obtido após a extração do óleo da polpa (amêndoa) por solvente e moagem fina (Reis, 2009). Na tabela 1 estão apresentados os valores nutricionais do farelo de babaçu, caracterizados por elevados teores de proteína e fibra bruta.

Tabela 1. Valores de matéria seca (MS), energia bruta $(\mathrm{EB})$, proteína bruta $(\mathrm{PB})$, extrato etéreo $(\mathrm{EE})$, fibra bruta (FB) e matéria mineral (MM) do farelo de babaçu (FB).

\begin{tabular}{lc}
\hline Parâmetros & FB \\
\hline MS (\%) & 92,41 \\
EB (kcal/kg) & 4207 \\
PB (\%) & 20,19 \\
EE (\%) & 2,15 \\
FB (\%) & 47,52 \\
MM (\%) & 4,06 \\
\hline
\end{tabular}

Fonte: Rostagno et al. (2011).

Carneiro et al. (2009) utilizaram níveis de inclusão do farelo de babaçu (0, 3, 6, 9 e 12\%) para frangos de corte na fase de 21 a 42 dias de idade e concluíram que o nível de inclusão de até $12 \%$ de farelo de babaçu nas dietas não prejudicou no peso final aos 42 dias de idade. Com a ressalva de que a utilização do farelo de babaçu pode ser vantajoso em períodos de entressafra do milho e da soja, permitindo a inclusão em até $6 \%$ nas dietas para frango de corte de 21 a 42 dias de acordo com as análises econômicas deste trabalho.

\section{Torta de babaçu}

A torta de babaçu é obtida através de extração parcial do óleo da polpa por processo de prensagem mecânica (expeller) (Reis, 2009).

$\mathrm{Na}$ tabela 2 estão apresentados os valores nutricionais da torta de babaçu. O seu elevado teor de extrato etéreo, quando comparado com o farelo de babaçu, deve-se ao processamento. O óleo não é retirado por completo e, portanto, conferindo maior teor de energia bruta. 
Santos Neta (2010) avaliaram níveis de inclusão da torta de babaçu $(0,4,8$ e $12 \%)$ na alimentação de frangos de corte no período de um a 21 dias de idade e concluíram que a torta de babaçu pode ser utilizada até o nível de $12 \%$.

Tabela 2. Matéria seca (MS), energia bruta (EB), proteína bruta $(\mathrm{PB})$, extrato etéreo (EE), fibra bruta (FB) e matéria mineral (MM) da torta de babaçu (TB).

\begin{tabular}{lc}
\hline Parâmetros & TB $^{1}$ \\
\hline MS $(\%)$ & 96,67 \\
EB $(\mathrm{kcal} / \mathrm{kg})$ & 4931 \\
PB $(\%)$ & 22,43 \\
EE $(\%)$ & 8,87 \\
FB $(\%)$ & - \\
MM $(\%)$ & $6,18^{2}$ \\
\hline
\end{tabular}

Fonte: Santos Neta (2010) e Farias Filho et al. (2012).

No entanto, Silva (2009) realizou dois experimentos com frangos de corte caipira da linhagem Label Rouge, o primeiro com frangos de 1 a 28 dias de idade e o segundo de 36 a 84 dias de idade. Avaliou níveis de inclusão de $0 \%$, $8 \%, 16 \%, 24 \%$ e $32 \%$ da torta de babaçu na ração a base de milho e farelo de soja em ambos os experimentos. $\mathrm{O}$ autor concluiu níveis máximos de inclusão de $8 \%$ e $32 \%$ para o primeiro e segundo experimento, respectivamente.

De acordo com os estudos realizados pode ser utilizado o nível de inclusão de até 32\% da torta de babaçu, entretanto, deve-se levar em consideração a idade e linhagem da ave. Sendo importante a avaliação dos custos e dos níveis menos onerosos para a sua produção.

\section{Farinha amilácea fina do babaçu}

A farinha amilácea fina do babaçu é extraída do mesocarpo do babaçu, possuindo como principal característica nutricional elevado teor de amido, podendo ser utilizada na composição de ração em substituição às fontes de alimentos energéticos (Reis, 2009). Atualmente é alvo de estudos para sua utilização na ração animal. No entanto, poucos estudos foram desenvolvidos para a obtenção de resultados em frangos de corte.

Na tabela 3 estão apresentados os valores nutricionais da farinha amilácea fina do babaçu, contudo, ocorre ampla variação na sua composição bromatológica. De acordo com diversos autores um dos problemas enfrentados pelos nutricionistas é a variação na composição química de um mesmo tipo de alimento. Porém esta variação é normal, principalmente em si tratando de alimentos de diferentes origens e processamentos, condição de cultivo e de solo, clima e cultivares (Albino, 1992).

Tabela 3. Valores de matéria seca (MS), energia bruta (EB), proteína bruta (PB), extrato etéreo (EE), fibra bruta (FB) e matéria mineral (MM) da farinha amilácea fina de babaçu (FAF).

\begin{tabular}{lcccc}
\hline Parâmetros & $\mathrm{FAF}^{1}$ & $\mathrm{FAF}^{2}$ & $\mathrm{FAF}^{3}$ (chuvoso) & $\mathrm{FAF}^{3}\left(\mathrm{seco}^{2}\right)$ \\
\hline MS (\%) & 84,0 & 86,27 & 89,846 & 91,185 \\
EB (kcal/kg) & 4354 & 3687 & 4221 & 4178 \\
PB (\%) & 3,5 & 1,91 & 2,897 & 3,485 \\
EE (\%) & 1,87 & 0,29 & 1,017 & 0,355 \\
FB (\%) & 9,4 & 9,69 & - & - \\
MM (\%) & 3,2 & 2,50 & - & - \\
\hline
\end{tabular}

Fonte: ${ }^{1}$ Reis (2009); ${ }^{2}$ Rostagno et al. (2011); ${ }^{3}$ Santos Neta (2010).

Santos Neta (2010) realizou um ensaio de metabolizabilidade da farinha amilácea fina do babaçu com frangos de corte em dois períodos: chuvoso e seco, obtendo os valores de energia metabolizável aparente e aparente corrigida de $2328 ; 1823 \mathrm{kcal} / \mathrm{kg}$ e 2260; $1794 \mathrm{kcal} / \mathrm{kg}$, respectivamente, e coeficiente de metabolizabilidade aparente da proteína bruta de 53,98 no período chuvoso e $32,29 \%$ no período seco. Os resultados de energia metabolizável e o coeficiente de metabolizabilidade aparente da proteína bruta foram maiores nos períodos chuvosos, indicando melhor aproveitamento do produto na época chuvosa. Nesta época, em função do crescimentos das plasntas, de modo geral, a composição é suprior.

\section{Dendê}

O dendezeiro (Elaeais guineensis Jaquim) é uma palmeira originária da costa oriental da África (Golfo da Guiné), sendo encontrada em povoamentos subespontâneos desde o Senegal até Angola e foi 
trazida ao Brasil a partir do século XV. O óleo originário desta palmeira, o azeite de dendê, é consumido há mais de 5.000 anos (Souza, 2000).

$\mathrm{Na}$ Tabela 4 é possível visualizar dados da produção do dendê em algumas regiões do Brasil, segundo dados do Instituto Brasileiro de Geografia e
Estatística (IBGE, 2013). Pará destaca-se, apesar de possuir menor área destinada à colheita e área colhida, por possui maior quantidade de dendê produzido e consequente maior renda com sua produção.

Tabela 4. Áreas destinadas à colheita e colhidas, quantidade produzida, rendimento médio e valor da produção dos principais produtos das lavouras permanentes, segundo as Grandes Regiões e as Unidades da Federação produtoras -2009 .

\begin{tabular}{llllll}
\hline \multicolumn{7}{c}{ Dendê (cacho de coco) } \\
$\begin{array}{l}\text { Grandes Regiões } \\
\text { produtoras }\end{array}$ & $\begin{array}{l}\text { Área destinada } \\
\text { à colheita (ha) }\end{array}$ & Área colhia (ha) & $\begin{array}{l}\text { Quantidade } \\
\text { produzida (t) }\end{array}$ & $\begin{array}{l}\text { Rendimento } \\
\text { médio (kg/ha) }\end{array}$ & $\begin{array}{l}\text { Valor } \\
\text { produção } \\
(1.000 \mathrm{R} \$)\end{array}$ \\
\hline Brasil & 103.913 & 103.904 & 1.122 .399 & 10.802 & 184.719 \\
Norte & 50.396 & 50.387 & 916.846 & 18.196 & 147.451 \\
Amazonas & 70 & 61 & 183 & 3000 & 82 \\
Pará & 50.326 & 50.326 & 916.663 & 18.214 & 147.368 \\
Nordeste & 53.517 & 53.517 & 205.553 & 3.840 & 37.269 \\
Bahia & 63.617 & 63.617 & 206.663 & 3.840 & 37.209 \\
\hline
\end{tabular}

Fonte: Instituto Brasileiro de Geografia e Estatística - (IBGE, 2013).

\section{Torta de dendê}

A torta de dendê é o produto resultante da polpa seca do dendê, após moagem e extração do seu óleo. Farias Filho et al. (2012) afirmaram que a torta de dendê é um produto não padronizado, pois possui diferenças nas formas de extração do óleo, locais de plantio, formas de colheita, dentre outros. Podendo, desta forma, dificultar a formulação de dietas para animais.

No Tabela 5 estão apresentados os valores nutricionais da torta do dendê correspondente aos meses de outubro, novembro e dezembro de 2004 e de janeiro de 2005.

Tabela. Teores de matéria seca (MS), proteína bruta (PB), extrato etéreo (EE), fibra bruta (FB), fibra em detergente neutro (FDN), fibra em detergente ácido (FDA), material mineral (MM) e energia bruta (EB) da torta de dendê.

\begin{tabular}{lcccccccc}
\hline Meses & MS, \% & PB, \% & EE, \% & FB, \% & FDA, \% & FDN, \% & MM, \% & EB,kcal/kg \\
\hline Outubro & 97,98 & 17,86 & 5,39 & 32,06 & 57,29 & 70,82 & 10,07 & 4,71 \\
Novembro & 97,68 & 19,14 & 6,31 & 16,54 & 45,28 & 66,99 & 6,41 & 4,71 \\
Dezembro & 97,02 & 18,55 & 5,85 & 18,41 & 47,61 & 68,24 & 9,09 & 4,95 \\
Janeiro & 98,12 & 17,32 & 5,25 & 21,69 & 49,57 & 78,24 & 5,73 & 4,81 \\
Média & 97,70 & 18,21 & 5,70 & 22,17 & 49,93 & 71,07 & 7,82 & 4,79 \\
\hline
\end{tabular}

Fonte: Farias Filho et al. (2012).

Percebe-se na tabela 5 que ocorre pequenas variações na composição bromatológica da torta de dendê dentro dos meses avaliados, observando maiores variações no teor de fibra bruta e matéria mineral.

Ezieshi \& Olomu (2004) comparando o desempenho de frangos de corte na fase inicial (1 a 35 dias de idade) e final ( 36 a 63 dias de idade) utilizando dietas com farelo de milho $(30 \%$ e $43,85 \%$ fase inicial e $34 \%$ e $44,95 \%$ fase final) e torta de dendê (30\% e $43,85 \%$ fase inicial e $34 \%$ a $44,95 \%$ fase final), concluíram que os melhores resultados foram obtidos com o farelo de milho. No entanto, ao observar somente as rações com torta de dendê verificou-se melhores resultados na fase final.

Farias Filho et al. (2012) utilizando dietas com níveis de torta de dendê $(0 \%, 5 \%, 10 \%, 15 \%$ e $20 \%$ de torta de dendê) nas fases de 21 a 35 dias de idade e 35 a 42dias de idade, concluiu que níveis de até $10 \%$ podem ser fornecidos para a 
fase de 21 a 35 dias de idade e até o nível de $20 \%$ para a fase de 35 a 42 dias de idade.

Silva (2011) avaliou os níveis de inclusão de $0 \%, 4 \%, 8 \%$ e $12 \%$ da torta de dendê para frangos de corte de crescimento lento nas fases, inicial (1 a 28 dias de idade), crescimento (29 a 56 dias de idade) e terminação (57 a 84 dias de idade) e verificou que para todas as fases de criação pode ser utilizado o nível de até $12 \%$ de inclusão da torta de dendê.

Contudo, o autor afirma, de acordo com os dados analisados, que as aves respondem melhor a utilização da torta de dendê na fase de terminação. Isto se deve ao fato de os animais, na fase de crescimento, precisarem de nutrientes prontamente disponíveis para seu desenvolvimento, conquanto, na fase final o trato gastrointestinal já está completamente desenvolvido, possibilitando melhor digestão e absorção.

\section{Girassol}

O girassol é uma planta originária das Américas e cultivada pelos povos indígenas desde 1000 a.C. para alimentação. Das suas sementes é extraído o óleo e a produção mundial ultrapassa 20 milhões de toneladas anuais do grão. No Brasil, a seu cultivo tem sido orientado mais para a produção de biodiesel, gerando o farelo e a torta que são direcionados para alimentação animal (Lasca, 2011).

Lin et al. (1974) afirmam a presença de um composto polifenólico (ácido clorogênico) na semente do girassol. Entretanto, Treviño et al. (1998) relatam que este composto age como inibidor de protease (tripsina) e lipase.

Portanto, Rostagno et al. (2011) sugerem recomendações prática e máxima da inclusão do farelo de girassol na ordem de $5 \%$ e $10 \%$ para frangos de corte na fase inicial e de $8 \%$ e $15 \%$ frango de corte em fase de crescimento, respectivamente.

\section{Farelo de girassol}

O farelo de girassol, obtido pela extração do óleo por solvente, tem sido uma boa alternativa para alimentação animal em substituição a outros grãos (Lasca, 2011).

Os valores nutricionais do farelo de girassol, dispostos no Tabela 6, possuem grande variabilidade na literatura (Villamide \& San Juan, 1998). Possui baixo teor de extrato etéreo e alto de proteína bruta, sendo classificado como alimento concentrado proteico, apesar de seu alto ter em fibra que, segundo Café (1993), diminui o valor de energia metabolizável e o aproveitamento dos nutrientes pelos animais nãoruminantes.

Tabela 6. Valores de matéria seca (MS), energia bruta (EB), proteína bruta (PB), extrato etéreo (EE), fibra bruta (FB) e matéria mineral (MM) de diferentes farelos de girassol.

\begin{tabular}{lcccccc}
\hline Parâmetros & \multicolumn{2}{c}{ Rostagno } & \multicolumn{2}{c}{ Rhone Poulenc } & Eurolysine & \multicolumn{2}{c}{ NRC (1998) } \\
\hline MS (\%) & 89,74 & 90 & 90 & 90 & 90 & 93 \\
EB (kcal/kg) & 4289 & - & - & - & - & - \\
PB (\%) & 30,22 & 29 & 34 & 37,4 & 26,8 & 42,2 \\
EE (\%) & 1,78 & 1,5 & 1,5 & 1,8 & 1,3 & 2,9 \\
FB (\%) & 25,73 & 25 & 23 & 26,1 & - & - \\
MM (\%) & 5,98 & 6 & 6 & 7,8 & - & - \\
\hline
\end{tabular}

Fonte: Tavernari et al. (2008).

Segundo Stringhini et al. (2006), apesar do seu alto teor protéico, o farelo de girassol apresenta deficiência de lisina para as rações de frangos de corte que podem variar entre $0,9 \mathrm{e}$ $2,83 \%$, dependendo do processamento (NRC, 2012).

Estudos realizados por Furlan et al. (2001) avaliaram cinco níveis de substituição da proteína do farelo de soja pela do farelo de girassol nas rações de frangos de corte $(10,20,30,40$ e $50 \%)$ e concluíram que até o nível de $30 \%$ de substituição, correspondente a $15 \%$ de inclusão do farelo de girassol, não afetou o desempenho dos animais.

Oliveira et al. (2003) concluíram que a inclusão de $15 \%$ do farelo de girassol, testado em 3 níveis $(0,15$ e $30 \%)$ com ou sem suplementação de lisina, pode ser usado sem afetar o desempenho geral e o rendimento de carcaça dos animais.

Tavernari et al. (2008) testando os níveis crescentes farelo de girassol em dietas, 
suplementadas com lisina, para frangos de corte, verificou que o nível de inclusão de $20 \%$ nas diferentes fases estudadas não afetou o desempenho e rendimento de carcaça dos animais.

\section{Torta de girassol}

De acordo com Lasca (2011), a torta de girassol é obtida pela extração do óleo por prensagem mecânica da semente a $80^{\circ} \mathrm{C}$, entretanto, San Juan \& Villamide (2000) citam que a partir de $1000 \mathrm{~g}$ de semente de girassol é possível obter $340 \mathrm{~g}$ de óleo e $660 \mathrm{~g}$ de torta.

$\mathrm{Na}$ tabela 7 estão apresentados os valores nutricionais da torta de girassol.

Tabela 7. Valores de matéria seca (MS), energia bruta $(\mathrm{EB})$, proteína bruta $(\mathrm{PB})$, extrato etéreo $(\mathrm{EE})$, fibra bruta $(\mathrm{FB})$ e matéria mineral $(\mathrm{MM})$ da torta de girassol (TG).

\begin{tabular}{lc}
\hline Parâmetros & TG \\
\hline MS (\%) & 91,10 \\
EB (kcal/kg) & 5509 \\
PB (\%) & 22,64 \\
EE (\%) & 28,04 \\
FB (\%) & 19,34 \\
MM (\%) & 4,25 \\
\hline
\end{tabular}

Fonte: Fonseca et al. (2007).

Fonseca et al. (2007) trabalhando com níveis de torta de girassol $(0,3,6,9,12 \%)$ com frangos de corte nas fases de 14 a 35 e 36 a 42 dias de idade, encontraram bons resultados na fase final, sendo possível incluir até o nível de $12 \%$. Já na fase de 14 a 35 dias de idade a inclusão da torta de girassol afetou negativamente o desempenho das aves. Esses mesmo autores relataram que o efeito sobre os parâmetros de carcaça corte e rendimento, foram penalizados detrimento do maior acúmulo de gordura.

\section{Mandioca}

Mandioca é o nome pelo qual é conhecida a espécie comestível e mais largamente difundida do gênero Manihot, composto por diversas variedades de raízes comestíveis. Conhecida por vários nomes, entre eles aipim, macaxeira, mandioca e em inglês recebe o nome de cassava (Souza \& Fialho, 2003).

Ainda de acordo com os mesmos autores a mandioca (Manihot esculenta Crantz) é um arbusto que teria tido sua origem mais remota no oeste do Brasil (sudoeste da Amazônia) e que, antes da chegada dos europeus à América, já estaria disseminado, como cultivo alimentar, até a Mesoamérica (Guatemala, México). Espalhada para diversas partes do mundo tem hoje a Nigéria como seu maior produtor. Mais de 80 países produzem mandioca, sendo que o Brasil participa com mais de $15 \%$ da produção mundial. A mandioca e seus resíduos podem ser utilizados como fontes alternativas de alimentos energéticos na ração animal.

\section{Raspa integral de mandioca}

A raspa de mandioca é obtida pela desidratação da mandioca na forma de pequenos pedaços (Souza \& Fialho, 2003).

Segundo Rostagno et al. (2011) as recomendações prática e máxima da inclusão da raspa de mandioca nas rações de frango de corte é de $5 \%$ e $20 \%$ na fase inicial e de $10 \%$ e $20 \%$ na fase de crescimento, respectivamente.

Nascimento et al. (2005) utilizaram a raspa de mandioca (níveis de $0,5,10,15,20$ e $25 \%$ em substituição ao milho) nas fases de 22 a 35 dias de idade e 36 a 42 dias de idade nas dietas para frangos de corte, recomendando que o melhor nível de substituição é o de 10,29\% nas rações de engorda dos frangos de corte, enquanto que na fase final, à medida que se aumentam os níveis da farinha, os resultados apresentam-se desfavoráveis.

\section{Farinha de mandioca}

A farinha de mandioca utilizada na formulação de ração de frangos de corte é obtida pela farinha desclassificada para o consumo humano (Souza \& Fialho, 2003).

Campello et al. (2009) realizaram experimento com frango de corte caipira substituindo o milho por farinha de mandioca em quatro níveis $0,18,36$, e $53 \%$, os resultados apontaram redução significativa do peso ao abate, mas não afetou o rendimento de carcaça, cortes comerciais ou vísceras comestíveis e ainda promoveu redução no acúmulo de gordura abdominal, concluíram ser uma alternativa quando a redução nos custos da ração compensar a diminuição no peso final das aves.

\section{Bagaço de mandioca}

O bagaço é obtido após prensagem para extração da fécula (Souza \& Fialho, 2003). No Tabela 8 estão apresentados os valores nutricionais da mandioca e seus subprodutos, sendo visível o baixo teor de proteína bruta e 
extrato etéreo tanto na mandioca quanto em seus subprodutos, no entanto, possui considerável valor energético, principalmente nos subprodutos.

Tabela 8. Valores nutricionais da mandioca fresca (MF), raspa de mandioca (RM), farinha integral de mandioca (FIM) e bagaço de mandioca (BM).

\begin{tabular}{lcccc}
\hline Parâmetros & MF & RM & FIM & BM \\
\hline Matéria seca (\%) & 33,88 & 87,29 & 92,29 & 88,71 \\
Energia bruta (kcal/kg) & 1322 & 3625 & 3794 & 3822 \\
Proteína Bruta (\%) & 1,72 & 1,65 & 2,09 & 0,57 \\
Extrato etéreo (\%) & 0,74 & 0,55 & 0,13 & 0,18 \\
Fibra bruta (\%) & 1,03 & 13,93 & 3,98 & 0,19 \\
Matéria mineral (\%) & 1,21 & 1,55 & 1,51 & 0,16 \\
\hline
\end{tabular}

Fonte: Embrapa (199).

Sousa et al., (2010a, b) ao trabalharem com bagaço de mandioca com níveis de inclusão de 0 , $5,10,15$ e $20 \%$ em rações para frango de corte, nas fases de 1 a 21 e 22 a 40 dias de idade, recomendaram os valores de $4,86 \%$ e $20 \%$, respectivamente.

\section{Alimentos de origem animal}

Nas últimas décadas houve uma expansão da produção de animais gerando maior quantidade de animais abatidos para atender a demanda mundial por carne. De acordo com Ramos \& Gomide (2007), o Brasil se consolidou o principal país exportador de carne bovina em 2003, com rebanho bovino estimado em 209 milhões de cabeças no ano de 2013 (IBGE, 2013). Já o efetivo de suínos brasileiro, segundo IBGE (2013), era de 38,9 milhões de cabeças com produção de carne suína em torno de 3,2 milhões de toneladas, representando $3,26 \%$ do mercado mundial. Outro setor que também tem se destacado no Brasil é o da produção de carne de frango, sendo o terceiro maior produtor mundial, estimada em 9,3 milhões de toneladas; e ainda o setor de pescado que de acordo com Rocha (2011), encontra-se estagnado com crescimento de 2003 para 2008 de 985.412 para 1.065.186 toneladas, respectivamente.

Dentre os diversos subprodutos gerados, têmse os subprodutos protéicos como as farinhas de carne e ossos, sangue, vísceras, penas e de peixe, criados a partir do abate dos animais; e os subprodutos energéticos, óleos e gorduras/sebos, obtidos dos tecidos animais após processamento industrial das carnes.

A classificação em óleo ou gordura deve-se a proporção ácidos graxos insaturados/saturados, portanto, quanto maior essa relação implicará em um produto na forma líquida.
Óleo e gordura são utilizados na alimentação de aves com o intuito de complementar a energia da ração, além de fornecer ácidos graxos essenciais, vitaminas lipossolúveis e melhorar o consumo; dentre outras funções.

No entanto, deve-se tomar o cuidado com a sua utilização. Andriguetto et al. (2002) relatam processos oxidativos que acometem as gorduras e ou óleo das rações, resultando na destruição das vitaminas lipossolúveis e biotina e do aminoácido metionina, fundamentais ao bom desempenho animal, além da redução do consumo pela piora de sua palatabilidade e aparecimento de casos de encefalomalácea, diátese exudativa, distrofia muscular, necrose dos tecidos, dentre outros.

Como consequência de tamanha produção animal e aumento de resíduos produzidos pelos frigoríficos e, dada à importância do uso de resíduos industriais, estudos são orientados para determinar o melhor nível de utilização desses subprodutos. Contudo, para a sua recomendação, deve-se ter o conhecimento de suas origens, pois é possível que esse item possa vir a se tornar um problema.

Segundo Bellaver (2001) é preciso ter conhecimento dos fatores anti nutricionais, bactérias, cheiro, cor, sabor que podem afetar a qualidade final dos rações produzidas, isso irá determinar quais os ingredientes que podem e os que não podem ser utilizados.

Dos resíduos gerados em frigoríficos, a partir do abate de animais, utilizados na alimentação de frangos de corte destacam-se:

\section{Farinha de carne e ossos}

A farinha de carne e ossos (FCO) é produzida por graxarias e frigoríficos a partir de ossos e tecidos animais, após a desossa completa da carcaça de bovinos, suínos, dentre outros 
animais. Este material é moído, cozido, prensado para extração da gordura e novamente moído. Não deve conter cascos, chifres, pêlos, conteúdo estomacal, sangue e outras matérias estranhas, e o cálcio não deve exceder a 2,5 vezes o nível de fósforo (Bellaver, 2001).

A farinha de carne e ossos com índices menores de $25 \%$ de cinzas, ou menos de $3,8 \%$ de fósforo, passa a ser denominado apenas de Farinha de Carne, possuindo aproximadamente 55 a $60 \%$ de proteína (Difisa, 1989).

De acordo com Bellaver (2001), Butolo (2002) a umidade; textura; altas temperaturas e tempo excessivo no digestor; excesso de gordura; contaminações do processo; contaminações com materiais estranhos ao processo e o tempo entre $\mathrm{o}$ abate e o processamento são fatores determinantes que afetam a qualidade das farinhas de carne e ossos.

$\mathrm{Na}$ tabela 9 estão apresentados os dados de diferentes trabalhos com farinha de carne e ossos de bovinos e sua composição em nutrientes. A diferença quanto ao "tipo", explícito na tabela, representa o valor em proteína bruta, o que dependendo da forma de processamento da carne e do sistema de abate e tipo animal, pode variar em seu valor nutricional.

Tabela 9. Teores de matéria seca (MS), energia bruta (EB), proteína bruta (PB), extrato etéreo (EE), fibra bruta (FB) e material mineral (MM) da farinha de carne e ossos.

\begin{tabular}{llllllll}
\hline Autores & Tipo & MS\% & EB kcal/kg & PB \% & EE \% & FB \% & MM \% \\
\hline Rostagno et al. (2011) & $36 \%$ & 92,91 & 3122 & 36,31 & 12,63 & - & 41,80 \\
Rostagno et al. (2011) & $46 \%$ & 93,27 & 3665 & 45,87 & 12,04 & - & 35,11 \\
Brumano et al. (2006) & $36 \%$ & 91,75 & 3066 & 37,56 & 10,56 & 0,80 & 40,06 \\
Brumano et al. (2006) & $45 \%$ & 90,72 & 3298 & 44,72 & 9,88 & 1,12 & 34,47 \\
\hline
\end{tabular}

Brumano et al. (2006) determinaram os valores de energia metabolizável aparente (EMA) e aparente corrigida (EMAn) para frangos de corte machos utilizando subprodutos de origem animal. Os valores de EMA (kcal/ $\mathrm{kg}$ ) e EMAn $(\mathrm{kcal} / \mathrm{kg})$, nos períodos de 21 a 30 e de 41 a 50 dias de idade, foram, respectivamente,1.330, 1.249 e $1.712,1.573$ para a farinha de carne e ossos $36 \% ; 1.418,1.391$ e $1.892,1.766$ para a farinha de carne e ossos $45 \%$, evidenciando melhor utilização da energia pelo frango na farinha de carne e ossos $45 \%$.

De acordo com Farias Filho et al. (2012), ao avaliarem a utilização da farinha de carne e ossos sobre o desempenho e rendimento de carcaça de frangos de corte, concluíram que a inclusão da farinha de carne e ossos nas dietas para frangos de corte prejudicou o desempenho nos períodos de 21 a 49 e de 0 a 49 dias de idade. No entanto, a fase de 1 a 21 dias de idade não foi prejudicada pela inclusão de FCO. Observaram ainda que a deposição de gordura abdominal é mais elevada em frangos alimentados com dietas contendo farinha de carne e ossos e as demais características de carcaça não foram comprometidas.

Junqueira et al. (2005) utilizando FCO com 37,51 e $41,58 \%$ de proteína bruta com dois níveis de inclusão (3 e 6\%) concluíram que não ocorreram diferenças no desempenho e nem nas características das carcaças avaliadas, no entanto, a gordura abdominal foi maior quando se utilizou FCO, indicando serem superestimados os valores de energia metabolizável empregados.

\section{Farinha de sangue}

De acordo com Bellaver (2001)(2001) a farinha de sangue (FS) é o produto resultante do processo de cozimento e secagem do sangue fresco obtido em frigoríficos. É um ingrediente com alto teor de proteína bruta, porém, sua utilização tem sido limitada em função do balanço inadequado de aminoácidos e baixa palatabilidade, bem como a falta de um processamento adequado. Portanto, quando utilizado no balanceamento de rações, deve-se levar em consideração o equilíbrio nutricional.

A composição bromatológica da farinha de sangue estabelecida por Rostagno et al. (2011) é de $92,90 \%$ de matéria seca; $5134 \mathrm{kcal} / \mathrm{kg}$ energia bruta; $83,50 \%$ proteína bruta; $0,46 \%$ extrato etéreo e $3,44 \%$ de material mineral.

Cancherini et al. (2005) trabalharam com pintinhos de 1 a 21 dias de idade, avaliando $6 \%$ de inclusão da farinha de sangue bovino em rações formuladas com base na proteína bruta (aminoácidos totais e digestíveis) e proteína ideal 
(relação lisina: metionina + cistina igual a 100:76), sobre o ganho de peso, consumo de ração e conversão alimentar, e observaram os melhores ganhos de peso com as dietas contendo farinha de sangue formuladas com base na proteína bruta.

\section{Farinha de penas hidrolisadas}

Segundo Bellaver (2001) a farinha de penas hidrolisadas (FP) é o produto resultante da cocção, sob pressão, de penas limpas e não decompostas, obtidas no abate de aves.

Apesar de possuir alto teor de proteína bruta, Abé (1981) relata que 85 a 90\% dessa proteína é queratina, portanto, apresenta baixa solubilidade e resistência à ação enzimática, o que limita sua utilização na alimentação das aves.

Nesse sentido, vários foram os trabalhos desenvolvidos para precisar o tipo e o tempo de processamento desta farinha para melhorar a sua qualidade. Em um deles, Fialho (1983) testou duas pressões e seis tempos de cozimento, concluiu relatando que estas duas variáveis influenciaram os valores protéicos da farinha de pena hidrolisada.

Brumano et al. (2006), em um experimento com aves para determinar os coeficientes de digestibilidade e os valores de aminoácidos digestíveis de farinhas de penas, verificou variações nestes coeficientes de 30,82 \% a $91,83 \%$. Nesta mesma investigação, devido a falta de padronização desse alimento, as diferentes amostras de farinhas testadas apresentaram ampla variação nos valores de digestibilidade dos aminoácidos, o que pode afetar o desempenho das aves.

Segundo Brumano et al. (2006) o percentual de inclusão da farinha de penas nas rações de aves é dependente da sua qualidade, mas vários pesquisadores adotam o limite máximo de $4 \%$.

Na Tabela 10 esta apresentada a composição bromatologica de diferentes trabalhos com farinhas de penas, onde pode ser observado a não padronização deste produto.

Tabela 10. Teores de matéria seca (MS), energia bruta (EB), proteína bruta (PB), extrato etéreo (EE), fibra bruta (FB) e material mineral (MM) da farinha de penas.

\begin{tabular}{lllllll}
\hline Autores & MS\% & EB kcal/kg & PB \% & EE \% & FB \% & MM \% \\
\hline Rostagno et al. (2011) & $89-91$ & $5206-5225$ & $74,91-83,63$ & $4,7-6,13$ & - & $2,42-3$ \\
Brumano et al. (2006) & 91,02 & 3983 & 56,30 & 7,26 & 0,69 & 23,63 \\
\hline
\end{tabular}

Nunes et al. (2005) avaliaram a farinha de penas, farinha de vísceras de aves e duas farinhas de carne e ossos 40 e $47 \%$, substituindo $20 \%$ da ração referência para frango de corte para determinação dos valores de energia metabolizável aparente (EMA). Os valores de EMA para a farinha de pena, farinha de vísceras de aves, farinha carne e ossos 1 e 2 foram 2774, 2676,2567 e $1657 \mathrm{kcal} / \mathrm{kg}$, respectivamente.

Holanda et al. (2009) ao avaliarem níveis crescentes de inclusão da farinha de penas hidrolisadas em dietas de frangos de corte, dos sete aos 42 dias de idade, concluíram que essa pode ser utilizada até o nível $8 \%$, sem causar prejuízo ao desempenho dos animais.

\section{Farinha de vísceras}

A farinha de vísceras (FV) é o produto resultante da cocção de vísceras de aves, sendo permitida a inclusão de cabeça e pés. Não deve conter penas, resíduos de incubatórios e outras matérias estranhas à sua composição e, ainda, não apresentar contaminação com casca de ovo (Bellaver, 2001).

No Tabela 11 estão apresentados os dados bromatologicos de diferentes trabalhos com farinha de vísceras, no qual é perceptível variação em todos os nutrientes.

Tabela 11. Teores de matéria seca (MS), energia bruta (EB), proteína bruta (PB), extrato etéreo (EE), fibra bruta (FB) e material mineral (MM) da farinha de vísceras.

\begin{tabular}{lllllll}
\hline Autores & MS\% & EB kcal/kg & PB $\%$ & EE \% & FB \% & MM \% \\
\hline Rostagno et al. (2011) & 93 & 4750 & 57,68 & 14,17 & - & 15,19 \\
Brumano et al. (2006) & 91,58 & 5039 & 60,70 & 20,18 & 0,59 & 10,86 \\
\hline
\end{tabular}


De acordo com Cancherini et al. (2005) avaliando ganho de peso, consumo de ração e conversão alimentar em pintinhos de 1 a 21 dias de idade, utilizando a inclusão de $6 \%$ de farinha de vísceras, com base na proteína bruta (aminoácidos totais e digestíveis) e proteína ideal (relação lisina: metionina + cistina igual a 100:76), observaram que os melhores resultados foram com farinha de vísceras de aves com base na proteína ideal.

Brumano et al. (2006) concluíram, em um ensaio de metabolismo, que os valores energia metabolizável aparente corrigida da farinha de vísceras foram de 3.442 e $3.209 \mathrm{kcal} / \mathrm{kg}$ e da farinha de penas, 3.219 e $3.323 \mathrm{kcal} / \mathrm{kg}$, quando determinados com aves de 16 a 23 dias e 30 a 38 dias de idade, respectivamente.

\section{Farinha integral de peixe}

A farinha integral de peixe (FIP) é o produto seco e moído, obtido de peixes inteiros de várias espécies, com ou sem extração de óleo (Bellaver, 2001).

Apesar dos estudos existentes com subprodutos protéicos de origem animal recomenda-se segundo Rostagno et al. (2011) níveis práticos e máximo da inclusão dos subprodutos de origem animal para frangos de corte na fase inicial e crescimento, estes são $\begin{array}{llll}\text { apresentados no } & \text { Tabela } & 12 .\end{array}$

Tabela 12. Nível prático e máximo da inclusão farinha de carne e osso (FCO $40 \%$ e 50\%), farinha de sangue (FS), farinha de vísceras (FV), farinha de pena (FP) e farinha integral de penas (FIP).

\begin{tabular}{lcccc}
\hline Alimento & \multicolumn{4}{c}{ Frango de corte } \\
\cline { 2 - 5 } & Prático & Inicial & \multicolumn{2}{c}{ Crescimento } \\
& 4 & Máximo & Prático & Máximo \\
\hline FCO 40\% & 5 & 7 & 4 & 5 \\
FCO 50\% & 1 & 8 & 5 & 10 \\
FS (\%) & 3 & 2 & 2 & 3 \\
FV (\%) & 1 & 7 & 3 & 4 \\
FP (\%) & 3 & 2 & 2 & 5 \\
FIP $(\%)$ & 7 & 2 & & 5 \\
\hline
\end{tabular}

Fonte: Rostagno et al. (2011)

Na Tabela 13 esta apresentada a composição bromatologica da farinha integral de peixe com 54 e $61 \%$ de proteína bruta.

De acordo com a EMBRAPA - Empresa brasileira de pesquisa agropecuária, as produções brasileiras anuais de sebo bovino industrial, realizado a partir de materiais gerados pelo abate de bovinos no ano de 2006, estão estimadas em 1.382.472 toneladas por ano (EMBRAPA, 2006).

Subproduto obtido em graxarias de frigoríficos bovinos, pela fusão de tecidos adiposos de bovino, tanto cavitários (visceral, mesentério, mediastinal, peri-renal e pélvico), como de cobertura (esternal, inguinal e subcutâneo), previamente lavados e triturados (DIPOA,1952).

No seu processo de fabricação recebe tratamento especial, visando aprimorar sua qualidade, principalmente para a utilização como ingrediente na alimentação animal por possuir grande valor energético. Nesta fase são retiradas as impurezas e a umidade, de forma a se obter um produto de qualidade superior. Segundo as normas do DIPOA - Departamento de Inspeção de Produtos de Origem Animal, artigo 308, ano 1952, o sebo bovino é caracterizado por possuir textura homogênea, tonalidade creme, máximo $1 \%$ de umidade e odor característico.

Tabela 13. Teores de matéria seca (MS), energia bruta (EB), proteína bruta (PB), extrato etéreo (EE), fibra bruta (FB) e material mineral (MM) da farinha integral de peixe (FIP).

\begin{tabular}{llllllll}
\hline Autores & FIP & $\begin{array}{l}\text { MS } \\
(\%)\end{array}$ & $\begin{array}{l}\text { EB } \\
(\mathrm{kcal} / \mathrm{kg})\end{array}$ & $\begin{array}{l}\text { PB } \\
(\%)\end{array}$ & $\begin{array}{l}\text { EE } \\
(\%)\end{array}$ & $\begin{array}{l}\text { FB } \\
(\%)\end{array}$ & $\begin{array}{l}\text { MM } \\
(\%)\end{array}$ \\
\hline Rostagno et al. (2011) & $54 \%$ & 92,06 & 4065 & 54,58 & 7,46 & - & 22,74 \\
Rostagno et al. (2011) & $61 \%$ & 91,71 & 4199 & 61,42 & 5,85 & - & 19,35 \\
\hline
\end{tabular}


Brumano et al. (2006) determinaram os valores de energia metabolizável aparente (EMA) e aparente corrigida (EMAn) utilizando farinha de peixe com frangos de corte machos, encontraram os valores de EMA (kcal/ $\mathrm{kg}$ ) e EMAn (kcal/ $/ \mathrm{kg})$, nos períodos de 21 a 30 e de 41 a 50 dias de idade, de 3.136, 3.055 e 3.183, 3.077 respectivamente.

\section{Sebo bovino}

Ao utilizar sebo bovino na alimentação de aves deve-se considerar a proporção de ácidos graxos insaturados/saturados, assim como o seu nível de energia. Acredita-se que o uso deste ingrediente, como fonte exclusiva de lipídeos na ração, possa diminuir o desempenho por proporcionar, segundo Gaiotto et al. (2000), menor formação de micelas no intestino delgado, por conseguinte menor o seu aproveitamento. Podendo ser utilizado, quando for viável economicamente, e associado a outras fontes de lipídios com menor proporção de ácidos graxos saturados/insaturados.

Gaiotto et al. (2000) avaliando sebo bovino, óleo de soja e óleo ácido de soja incluídos individualmente na ração na proporção de $4 \%$ e avaliando suas misturas na proporção de $2 \%$ de cada produto ( $2 \%$ sebo bovino : $2 \%$ óleo de soja;
$2 \%$ sebo bovino : $2 \%$ óleo ácido de soja; $2 \%$ óleo de soja : $2 \%$ óleo ácido de soja) na ração de frango de corte, nas fases de 1 a 21, 22 a 35 e 36 a 42 dias de idade, concluíram que o desempenho obtido pelas aves com a adição de óleo de soja aos outros tratamentos e o uso de misturas de óleo de soja com partes iguais de óleo ácido de soja ou de sebo bovino resultou em desempenho equivalente ao obtido com o óleo de soja adicionado unicamente.

Ferreira (2004) trabalhando com óleo de soja, sebo de bovino e suas combinações (0:100; $25: 75 ; 50: 50 ; 75: 25 ; 100: 0)$ em rações para frangos de corte, avaliou a digestibilidade e o desempenho, sendo a digestibilidade avaliada no período de 25 a 32 dias, concluindo que os maiores valores energéticos das misturas foram encontrados nos tratamentos que tiveram maiores proporções de óleo de soja. Para os parâmetros de desempenho (peso médio, consumo de ração, conversão alimentar e ganho de peso) durante o período de 21 a 41 dias de idade, não houve influência significativa das diferentes misturas.

No Tabela 14 são apresentados os dados de diferentes trabalhos com sebo bovino e sua composição em matéria seca e energia.

Tabela 14. Valores de matéria seca (MS\%), energia bruta (EB kcal/kg), energia metabolizável (EM kcal/kg), energia metabolizável aparente (EMA $\mathrm{kcal} / \mathrm{kg}$ ), energia metabolizável aparente corrigida para balanço de nitrogênio (EMAn kcal/kg) encontrados no sebo bovino por diferentes autores.

\begin{tabular}{lccccc}
\hline Autores & MS (\%) & EB (kcal/kg) & EM, kcal/kg & EMA, kcal/kg & $\begin{array}{l}\text { EMAn, } \\
\mathrm{kcal} / \mathrm{kg}\end{array}$ \\
\hline Fialho et al. (1991) & 99,9 & - & 8037 & - & - \\
Albino et al. (1992) & 99,41 & 9375 & 7425 & - & - \\
Nascif et al. (2004) & 99,3 & 9390,72 & - & 7282 & 7278 \\
Rostagno et al. (2011) & 99,39 & 9408 & 7401 & - & - \\
\hline
\end{tabular}

\section{Banha suína}

De acordo com a EMBRAPA, as produções brasileiras anuais de banha suína industrial realizada a partir de materiais gerados pelo abate de suínos no ano de 2006 foram estimadas em 194.876 toneladas por ano (EMBRAPA, 2006).

Segundo artigo 282 do DIPOA (1952) entende-se por "banha comum" o produto obtido pela fusão de tecidos adiposos frescos de suínos, de mistura com ossos, pés, recorte de bochechas apara de carne e línguas, lábios, focinhos, rabos, traquéia, pâncreas, recortes de produtos curados de suínos, esôfagos, torresmos, gordura e de decantação de tecidos adiposos de suínos, gordura de cozimento e inclusive essas mesmas matérias-primas quando procedentes de animais destinados a esse aproveitamento pela Inspeção.

A banha suína é caracterizada por possuir cor branca ou branca-mate, odor a torresmo, textura homogênea ou ligeiramente granulada, umidade no máximo $1 \%$ e ausência de ranço.

No Tabela 15 são apresentados os dados de diferentes trabalhos com banha suína e sua composição em matéria seca e energia. 
Tabela 15. Valores de matéria seca (MS\%), energia bruta (EB kcal/kg), energia metabolizável (EM kcal/kg), energia metabolizável aparente (EMA $\mathrm{kcal} / \mathrm{kg}$ ), energia metabolizável aparente corrigida para balanço de nitrogênio (EMAn $\mathrm{kcal} / \mathrm{kg}$ ) encontrados na banha suína por diferentes autores.

\begin{tabular}{lccccc}
\hline Autores & MS (\%) & EB (kcal/kg) & EM (kcal/kg) & EMA (kcal/kg) & EMAn, kcal/kg \\
\hline Fialho et al. (1991) & 99,2 & - & 8352 & - & - \\
Albino et al. (1992) & 99,83 & 9445 & 7660 & - & - \\
Nascif et al. (2004) & 99,6 & 9322,07 & - & 7594 & 7589 \\
Rostagno et al. (2011) & 99,55 & 9369 & 8080 & - & - \\
\hline
\end{tabular}

Entre os diferentes autores encontram-se pequena diferenças nos valores energéticos da banha suína. No entanto, deve-se tomar cuidado ao utilizá-la, devendo sempre considerar os níveis energéticos como também as impurezas nela encontrada, pois estes fatores influenciam na composição, qualidade e durabilidade das rações (Fialho et al., 2009).

\section{Óleo de peixe}

No artigo 471 do DIPOA (1952) defini-se por "óleo de pescado" o subproduto líquido obtido pelo tratamento de matérias-primas pela cocção a vapor, separado por decantação ou centrifugação e filtração. Suas principais características são a cor amarelo claro ou amarelo âmbar, máximo $1 \%$ de impureza, $10 \%$ de umidade e não deve conter substâncias estranhas ou outros óleos animais ou vegetais.

Junqueira et al. (2005) conduziram um experimento com o intuito de determinar os valores energéticos do óleo de peixe para frangos de corte e encontraram os valores de 9969 $\mathrm{kcal} / \mathrm{kg}$ de energia bruta e $8715 \mathrm{kcal} / \mathrm{kg}$ de EMAn (energia metabolizável aparente).

O uso do óleo de peixe na dieta de aves é importante e deve ser considerado, pois aumenta os níveis de deposição de ácidos graxos insaturados na carne de frango agregando valor e tornando este produto mais saudável, no entanto, deve-se ter o cuidado com o atendimento das exigências energéticas das aves e ao sabor da carne de frango, pois dependendo da qualidade e quantidade pode causar alterações de ranço.

\section{Óleo de frango}

De acordo com Bellaver (2001) o óleo de frango é um resíduo do processamento, com aquecimento controlado, das partes não comestíveis de aves abatidas, seguido de prensagem, decantação ou filtragem da gordura, contendo exclusivamente resíduos do abate de aves. No caso de utilização de antioxidantes, deve-se descrever o tipo e quantidade.

No Tabela 16 são apresentados os dados de diferentes trabalhos com óleo de frango e sua composição em matéria seca e energia.

Tabela 16. Valores de matéria seca (MS\%), energia bruta (EB kcal/kg), energia metabolizável (EM kcal/kg), energia metabolizável aparente (EMA kcal $/ \mathrm{kg}$ ), energia metabolizável aparente corrigida para balanço de nitrogênio (EMAn kcal/kg) encontrados no óleo de frango por diferentes autores

\begin{tabular}{llllll}
\hline Autores & MS $(\%)$ & EB $(\mathrm{kcal} / \mathrm{kg})$ & EM $(\mathrm{kcal} / \mathrm{kg})$ & EMA $(\mathrm{kcal} / \mathrm{kg})$ & EMAn $(\mathrm{kcal} / \mathrm{kg})$ \\
\hline Fialho et al. (1991) & 99,5 & & 8268 & & \\
Albino et al. (1992) & 99,9 & 7668 & & & \\
Nascif et al. (2004) & 99,6 & 9230,14 & & 8553 & 8545 \\
Rostagno et al. (2011) & 99,6 & 9282 & 8681 & & \\
\hline
\end{tabular}

Racanicci et al. (2008) conduziram um experimento com pintinhos adicionando $4 \%$ de óleo de vísceras de aves fresco ou oxidado à ração a base de milho e farelo de soja, com o objetivo de avaliar os efeitos nas rações, sobre o desempenho de frango de corte e a estabilidade oxidativa da carne de sobrecoxa congelada. Verificaram que não resultou em prejuízo ao desempenho zootécnico, nem ao rendimento de carcaça dos frangos, porém provocou redução no rendimento do peito, e a carne de sobrecoxa apresentou menor estabilidade oxidativa, devido ao maior acúmulo de compostos de ranço após, seis meses de armazenamento.

\section{Considerações finais}

A produção industrial no Brasil dá origem a volumes elevados de resíduos. Há diversos 
estudos sobre o aproveitamento desses resíduos ou subprodutos na alimentação de frangos de corte, devendo ter atenção especial à utilização em substituição ao milho e farelo de soja, principais ingredientes energético e protéico, respectivamente, utilizados na alimentação das aves. Ao utilizar subprodutos para substituir esses ingredientes, as suas características bromatológicas devem atender às exigências nutricionais dos frangos de corte.

Por isso se faz necessário à avaliação bromatológica do subproduto antes de sua utilização na ração, por não ser produtos padronizados, ocorrendo grandes variações de nutrientes, além de avaliação da eficiência econômica de utilização do subproduto como inclusão ou substituição nas rações de frangos de corte.

\section{Referências Bibliográficas}

Abé, P. T. 1981. Avaliação enérgetica e nutritiva da farinha de pena e sua utilização na alimentação de frangos de corte e poedeiras. 1981. Zootecnia. Universidade Federal de Viçosa, Viçosa.

Albino, L. F. T. 1992. Determinaçao dos valores de energía metabolizável aparente e verdadeira de alguns alimentos para aves, usando diferentes métodos. Revista da Sociedade Brasileira de Zootecnia, 21, 10471058.

Abdalla, A.L.; Silva Filho, J.C. Da; Godoi, A.R. De; Carmo, C. De A.; Eduardo, J.L. De P. Utilização de subprodutos da indústria de biodiesel na alimentação de ruminantes. Revista Brasileira de Zootecnia, Viçosa - MG, v.37, p.260-258, 2008.

Andriguetto, J. M; Perly, L; Minardi, I; Gemael, A; Flemming, J. S; Souza, G. A; Filho, A. B. Avaliação do valor energético dos alimentos. In: Nutrição animal: As bases e os fundamentos da nutrição animal - Os alimentos. São Paulo: Nobel, 2002. Capítulo VII, p.256- 268.

Araújo, G. C. De; Bueno, M. P.; Bueno, V.P.; Sproesser, R. L.; Souza, I. F. De. Cadeia produtiva da avicultura de corte: avaliação da apropriação de valor bruto nas transações econômicas dos agentes envolvidos. Revista Gestão e Regionalidade, v. 24, n. 72, 2008.

Bellaver, C. 2001. Ingredientes de origem animal destinados à fabricação de rações. Simpósio sobre ingredientes na alimentação animal, 1, $1-23$.

Brumano, G., Gomes, P. C., Albino, L. F. T., Rostagno, H., Generoso, R. \& Schmidt, M. 2006. Composição química e valores de energia metabolizável de alimentos protéicos determinados com frangos de corte em diferentes idades. Revista Brasileira de Zootecnia, 35, 2297-2302.

Butolo, J. E. 2002. Qualidade de ingredientes na alimentação animal. Butolo, Campinas.

Cafe, M.B. Estudo do valor nutricional da soja integral processada para aves. Jaboticabal, Universidade Estadual Paulista, 1993. 97p. Dissertação (Mestrado em Zootecnia) Universidade Estadual Paulista, 1993.

Campello, C. C., Santos, M. d. S. V., Anjos Leite, A. G., Rolim, B. N., Cardoso, W. M. \& Souza, F. M. 2009. Características de carcaça de frangos tipo caipira alimentados com dietas contendo farinha de raízes de mandioca. Ciência Animal Brasileira, 10, 1021-1028.

Cancherini, L. C., Junqueira, O. M., Oliveira, M. C., Andreotti, M. \& Barbosa, M. 2005. Utilização de subprodutos de origem animal em dietas formuladas com base em proteína bruta e proteína ideal para frangos de corte de 1 a 21 dias de idade. Revista Brasileira de Zootecnia, 34, 529-534.

Carneiro, A. P. M.; Pascoal, L. A. F.; Watanabe, P. H.; Santos, I. B.; Lopes, J. M.; Arruda, J. C. B; Farelo de babaçu em rações para frangos de corte na fase final: desempenho, rendimento de carcaça e avaliação econômica. Ciência Animal Brasileira, Goiânia -GO, v.10, n. 1, 2009.

Costa, M. C. R. Da; Silva, C. A. Da; Pinheiro, J. W.; Fonseca, N. A. N.; Souza, N. E. De; Visentainer, J. V.; Beler, J.C.; Borosky, J. C.; Mourinho, F. L.; Agostini, P Da S. Utilização da torta de girassol na alimentação de suínos nas fases de crescimento e terminação: efeitos no desempenho e nas características de carcaça. Revista Brasileira de Zootecnia, Viçosa - MG, v.34, n.5 p.1581-1588, 2005.

Divisão De Fiscalização De Alimentos Para Animais - Difisa. 1989. Padrões oficiais de matérias primas destinadas à alimentação animal. Brasília. 40p.

D.I.P.O.A-Departamento de Inspeção de Produtos de Origem Animal (1952). 
Disponível

em: <ttp://www.agricultura.gov.br/arq_editor/file/ Aniamal/MercadoInterno/Requisitos/Regulam entoInspecaoIndustrial.pdf $>$ Acesso em: 23/09/2011.

Ezieshi, E. \& Olomu, J. 2004. Comparative performance of broiler chickens fed varying levels of palm kernel cake and maize offal. Pakistan Journal of Nutrition, 3, 254-257.

FAPRI. 2015. Food and Agricultural Policy Research Institute. In: Database, W. A. O. (ed.) Food and Agricultural Policy Research Institute. Iowa State University and University of Missouri-Columbia Ames, IA, USA.

Faria Filho, D. E.; Faria, D. E.; Junqueira, O. M.; Rizzo, M. F.; Araújo, L. F.; Araújo, C. S. S. Avaliação da farinha de carne e ossos na alimentação de frangos de corte. Revista Brasileira de Ciência Avícola, v. 4, n. 1, jan/mar, 2002.

Farias Filho, R. V.; Rabello, C. B. V.; Albuquerque, C. Da S.; Lima Filha, O. da S. Determinação da analise bromatológica da torta de dendê, 2005. Anais... Zootec Campo Grande - MS, 2005.

Farias Filho, R. V.; Rabello, C. B.V.; Silva, E. P. Da; Lima, M. B. De; Souza, G. S . Avaliação da torta de dendê no desempenho de frangos de corte de 21 a 35 dias de idade. Anais... Zootec Recife - PE, 2006.

Farias, L. N. Dinâmica da fermentação ruminal de co-produtos do babaçu utilizando a técnica in vitro semi automática de produção de gases. Teresina - PI, 2008 (Dissertação de mestrado - UFPI), 54p. 2008.

Farias Filho, L., Vasconcelos, V., Carvalho, F. \& Sarmento, J. 2012. Dinâmica da fermentação ruminal de coprodutos do babaçu por meio da técnica in vitro semiautomática de produção de gases. Arquivo Brasileiro de Medicina Veterinaria e Zootecnia, 64, 1275-1283.

Ferreira, A. F. 2004. Valor nutricional do óleo de soja, sebo bovino e de suas combinações em rações para frangos de corte. Zootecnia. Universidade Federal do Mato Gro, Campo Grande.

Fialho, E. T. \& Barbosa, H. P. 2008. Alimentos alternativos para suínos. UFLA/FAEPE, Lavras.
Fonseca, N. A. N.; Pinheiro, J. W.; Brunelli, S. R.; Silva, C. A.; Sazaka, J. H. Torta de girassol na alimentação de frangos de corte. 2007, Anais... Londrina - PR, 2007.

Fonseca, N.A.N.; Pinheiro, J.W.; Brunelli, S.R.; Silva, C.A.; Cabrera, L.; Santos, D.D.; Sazaka, J. H.; Souza, L.F.A. Determinação dos valores energéticos e dos coeficientes de digestibilidade dos nutrientes da torta de girassol para frangos de corte. 2007, Anais... Londrina - PR, 2007.

Furlan, A. C., Mantovani, C., Murakami, A. E., Moreira, I., Scapinello, C. \& Martins, E. N. 2001. Utilização do farelo de girassol na alimentação de frangos de corte. Revista Brasileira de Zootecnia, 30, 158-164.

Gaiotto, J. B., Menten, J., Racanicci, A. \& Lafigliola, M. 2000. Óleo de soja, óleo ácido de soja e sebo bovino como fontes de gordura em rações de frangos de corte. Revista Brasileira de Ciência Avícola, 2, 219-227.

Gomes, F. A.; Fassani, E. J.; Rodrigues, P. B.; Filho, J. C. Da S. Valores Energéticos De Alguns Alimentos Utilizados Em Rações Para Codornas Japonesas. Revista Brasileira $e$ Zootecnia, 36, 396-402, 2007.

Holanda, M. A. C., Ludke, M. C. M. M., Ludke, J. V., Holanda, M. C. R., Rabello, C. B.-V., Dutra Júnior, W. M., Vigoderis, R. B. \& Costa, A. A. G. 2009. Desempenho e características de carcaças de frangos de corte recebendo dietas com farinha de penas hidrolisada. Revista Brasileira de Saúde e Produção Animal, 10.

IBGE. 2013. Contas nacionais trimestrais. Jul.set. 2013. 20th ed. Available in: www.ibge.gov.br, Rio de Janeiro, BR.

Junqueira, O. M., Andreotti, M. d. O., Araújo, L. F., Duarte, K. F., Cancherini, L. C. \& Rodrigues, E. A. 2005. Valor energético de algumas fontes lipídicas determinado com frangos de corte. Revista Brasileira de Zootecnia, 34, 2335-2339.

Lasca, D. H. De C. Girassol (Helianthus Annus L.). Disponível Em: <Http://Www.Agrobyte.Com.Br/Girassol.Htm $>$ Acesso Em: 17/10/2011.

Machado, G. C., Chaves, J. B. P. \& Antoniassi, R. 2006. Composição em ácidos graxos e caracterização física e química de óleos 
hidrogenados de coco babaçu. Revista Ceres, 53,463 .

Nascif, C.C.; Gomes, P. C.; Albion, L. F. T.; Rostagno, H. S. Determinação dos valores energéticos de alguns óleos e gorduras para pintos de corte machos e fêmeas aos 21 dias de idade. Revista Brasileira de Zootecnia, 33, 375-385, 2004.

Nascimento, G., Costa, F. G. P., Amarante Junior, V. \& Barros, L. R. 2005. Efeitos da substituição do milho pela raspa de mandioca na alimentação de frangos de corte, durante as fases de engorda e final. Ciência $e$ Agrotecnologia, 29, 200-207.

NRC. 2012. Nutrient requirements of swine, 7th rev. edn. Natl. Acad. Press, Washington, DC., Washington.

Nunes, R. V., Pozza, P. C., Nunes, C. G. V., Campestrini, E., Kühl, R., Rocha, L. \& Costa, F. G. P. 2005. Valores energéticos de subprodutos de origem animal para aves. Revista Brasileira de Zootecnia, 34, 12171224.

Oliveira, M., Martins, F., Almeida, C. \& Moura, C. 2003. Efeito da inclusão de bagaço de girassol na ração sobre o desempenho e rendimento de carcaça de frangos de corte. Revista Portuguesa de Zootecnia, 10, 107116.

Racanicci, A. M. C., Menten, J. F. M., Arce, M. \& Pino, L. M. 2008. Efeito do uso de óleo de vísceras de aves oxidado na ração de frangos de corte sobre o desempenho, a composição da carcaça e a estabilidade oxidativa da carne da sobrecoxa. Revista Brasileira de Zootecnia, 37, 443-449.

Ramos, E. M. \& Gomide, L. A. M. 2007. Avaliação da qualidade de carnes: fundamento $e$ metodologias. Universidade Federal de Viçosa, Viçosa.

Reis, D. 2009. Estudo da composição nutricional e dos coeficientes de digestibilidade da farinha amilácea fina do babaçu determinada com suínos nas fases de crescimento e terminação. Zootecnia. Universidade Federal de Tocantins, Araguaína.

Rocha, I. P.; Rocha, D. M. Panorama da produção mundial e brasileira de pescado, com ênfase para o segmento da aquicultura. Disponível Em <Http://Www.Abccam.Com.Br/Abcc/Images/
Stories/Publicacoes/13_-

_Panorama_Da_Produo_Mundial E Brasileira De Pescado.Pdf>. Acesso Em: 14/03/2012

Rostagno, H. S., Albino, L. F. T., Donzele, J. L., Gomes, P. C., Oliveira, R. d., Lopes, D. C., Ferreira, A. S., Barreto, S. \& Euclides, R. F. 2011. Composição de alimentos e exigências nutricionais. Tabelas brasileiras para aves $e$ suínos.

San Juan, L. \& Villamide, M. 2000. Nutritional evaluation of sunflower seed and products derived from them. Effect of oil extraction. British Poultry Science, 41, 182-192.

Santos Neta, E. 2010. Avaliação de subprodutos do babaçu (Palmae: Orbignya martiana) na alimentação de frangos de corte. Zootecnia. Escola de Medicina Veterinária e Zootecnia, Agraguaína.

Silva, E. G. Torta de dendê na alimentação de frangos de crescimento lento criados em sistema caipira. 2011. 51 P. (Dissertação de Mestrado). Universidade Federal do Tocantins - Araguaína, 2011.

Silva, R. F. Avaliação nutricional da torta de babaçu e sua utilização em dietas para frangos de corte Label Rouge. 2009. 67 P. (Tese de Doutorado). Universidade Federal de Goiás Goiânia, 2009.

Sousa, J. P. L.; Rodrigues, K. F.; Santos Neta, E. R. Dos; Parente, I. P.; Vaz, R. G. M. V.; Demuner, L. F. Inclusão do bagaço de mandioca (Manihot esculenta Crantz) em dietas de frangos de corte na fase de 1 a 21 dias de idade. Anais... Salvador: Sociedade Brasileira de Zootecnia, 2010a. CD-ROM.

Sousa, J. P. L.; Rodrigues, K. F.; Santos Neta, E. R. Dos; Parente, I. P.; Vaz, R. G. M. V.; Albino, L. F. T. Inclusão do bagaço de mandioca (Manihot esculenta Crantz) em dietas de frangos de corte na fase de 22 a 40 dias de idade. Anais... Salvador: Sociedade Brasileira de Zootecnia, 2010b. CD-ROM.

Souza, L. S. \& Fialho, J. F. 2003. Cultivo da mandioca para a região do Cerrado. Embrapa Mandioca e Fruticultura, 8.

Stringhini, J. H., Café, M. B., Fernandes, C. M., Andrade, M. L., Rocha, P. T. \& Leandro, N. S. M. 2006. Avaliação do valor nutrritivo do farelo de girassol para aves. Ciência Animal Brasileira, 1, 123-126. 
Tavernari, F. C., Albino, L. F. T., Dutra, W. M., Júnior, G. R. L., Nery, L. R. \& Maia, R. C. 2008. Farelo de girassol: composição e utilização da aimentação de frango de corte. Revista Eletrônica Nutritime, 5, 638-647.

Teixeira, M. A. Caracterização energética do babaçu e análise do potencial de cogeração. 2010. 192 P. (Tese de Doutorado). Universidade Estadual de Campinas Faculdade de Engenharia Mecânica Campinas, 2003.

Treviño, J., Rebolé, A., Rodríguez, M. L., Ortiz, L. T., Centeno, C. \& Alzueta, C. 1998. Nutritional effect of chlorogenic acid fed to growing broiler chicks. Journal of the Science of Food and Agriculture, 76, 156-160.
Villamide M.J.; San Juan L.D. Effect of Chemical composition of sunflower seed meal on its true metabolizable energy and amino acid digestibility. Poultry Science, 77, $1884-$ 1892, 1998.

Recebido em Dezembro 2, 2014

Aceito em Maio 27, 2015

License information: This is an open-access article distributed under the terms of the Creative Commons Attribution License, which permits unrestricted use, distribution, and reproduction in any medium, provided the original work is properly cited 